\title{
MÉTODOS CIENTÍFICOS EM ESTUDOS SOBRE EMPREENDEDORISMO NO SETOR PÚBLICO: UMA REVISÃO SISTEMÁTICA DE LITERATURA
}

Antonio Vagner Almeida Olavo ${ }^{1}$

Magnus Luiz Emmendoerfer ${ }^{2}$

Alessandro Carlos Da Silva Junior ${ }^{2}$

Mateus Cerqueira Anicio Morais ${ }^{2}$

${ }^{1}$ Universidade Federal de Viçosa/ Departamento de Administração e Contabilidade/ Universidade Federal do Amazonas/ Instituto de Natureza e Cultura

${ }^{2}$ Universidade Federal de Viçosa/ Departamento de Administração e Contabilidade 


\section{MÉTODOS CIENTÍFICOS EM ESTUDOS SOBRE EMPREENDEDORISMO NO SETOR PÚBLICO: UMA REVISÃO SISTEMÁTICA DE LITERATURA}

Resumo: O estudo teve como objetivo avaliar a utilização dos métodos científicos utilizados nas pesquisas sobre empreendedorismo no setor público no contexto brasileiro. Utilizou-se a Revisão Sistemática da Literatura. As buscas foram realizadas nas bases de dados nacionais Spell e Scielo. Para realização das buscas, utilizou-se das seguintes palavras-chave em língua portuguesa: "empreendedorismo público", "empreendedorismo no setor público", intraempreendedorismo no setor público" e "empreendedorismo político". O período compreendeu entre 2009 e 2019 . A busca inicial resultou em 98 artigos. A análise dos dados envolveu a leitura do título, resumo e metodologia. Após essas etapas, foram identificados 16 artigos que atenderam aos critérios de inclusão na revisão. Como resultados, identificou-se uma predominância de estudos qualitativos, a partir da pesquisa documental, entrevista, questionários, revisão de literatura e bibliográfica, observação participante e diário de campo. Conclui-se ser necessário avanços quanto a utilização dos métodos científicos em estudos sobre empreendedorismo no setor público brasileiro.

Palavras-chave: Empreendedorismo no setor público. Literatura Nacional. Métodos científicos. Revisão sistemática da literatura.

\section{$1 \quad$ Introdução}

O empreendedorismo no setor público enquanto fenômeno de estudo surge na busca de solução para resolver problemas complexos tanto do Estado quanto da sociedade, que exige de acordo Osborne e Gaebler (1995) organizações públicas flexíveis, adaptáveis que possam garantir serviços públicos de qualidade. Esta percepção de modernização do Estado, antes era vista somente no setor privado (VALADARES; EMMENDOERFER, 2015). Compreende-se que o empreendedor é um indivíduo ou um coletivo que realizam atividades voltadas para a inovação no setor público (EMMENDOERFER, 2019).

Neste sentido, esses atores são propulsores da inovação no setor público (COELHO, 2010; LAPOLLI; GOMES, 2017). Assim, os empreendedores no setor público são indivíduos que estão ligados direto ou indiretamente com o governo e que buscam realizar atividades inovativas nos serviços e/ou produtos que geram valor para os cidadãos. De acordo com Emmendoerfer (2019) esses indivíduos podem ser institucionais (intraempreendedores) ou de politicas públicas. Sendo o primeiro interno à organização pública, que operaciona projetos e introduz processos de mudanças e o segundo, com o foco mais externo e apresenta propostas de políticas públicas, denominado por Kingdon (2003), como empreendedor político.

Além dos indivíduos, há que consideram as inovações incrementais ou radicais que eles produzem para melhorar a eficiência e a efetividade dos serviços públicos, bem como para o fomento da cultura empreendedora e da geração de riquezas por meio de organizações, públicas ou não.

A manifestação de um fenômeno profundamente identificado com o setor privado, como é o empreendedorismo, em um ambiente historicamente reconhecido como lento e burocrático, 
com é o setor público, tem despertado a curiosidade de diversos autores, que procuram entender as características de um objeto que aparenta ser de imediato oximoro. Nesse contexto, Creswell (2003) salienta a importância da qualidade e pluralidade de métodos e de paradigmas para a ampliação do conhecimento científico sobre determinado tema. Nesta pesquisa, entende-se que a qualidade do uso dos métodos científicos empregados em estudos sobre empreendedorismo no setor público é crucial para o melhor entendimento sobre esse fenômeno. E o que tem sido feito no Brasil, Brasil?

Este artigo busca compreender por meio da revisão sistemática da literatura o rigor e a confiabilidade dos métodos científicos utilizados em estudos sobre o empreendedorismo no setor público no Brasil.

Frente ao exposto, questiona-se: De que forma os métodos científicos tem sido utilizados em estudos sobre empreendedorismo no setor público no contexto brasileiro? Para responder a esta questão realizou-se uma revisão sistemática de literatura com o objetivo de avaliar a utilização dos métodos científicos aplicados nas pesquisas sobre empreendedorismo no setor público no contexto brasileiro.

\section{Procedimentos metodológicos}

Trata-se de uma Revisão Sistemática de Literatura (RSL) de artigos científicos publicados no Brasil com o tema empreendedorismo no setor público. De acordo com Dresch, Lacerda Antunes Júnior (2015), as RSLs são estudos secundários que visam mapear, encontrar, avaliar, consolidar os estudos primários, bem como identificar lacunas de estudos. Para a realização deste estudo, foram seguidos os critérios apontados pela metodologia PRISMA tendo como base a tradução de Galvão, Pansani e Harrad (2015). O PRISMA foi utilizado neste estudo por estabelecer um conjunto de protocolos que conferem transparência ao método de revisão sistemática, sendo utilizado para identificar os artigos voltados para o empreendedorismo no setor público.

Como base para a realização das buscas dos artigos foram eleitas as bases de dados Spell (Scientific Periodicals Electronic Library) e Scielo (Scientific Electronic Library Online). A primeira trata-se de uma base nacional consolidada que disponibiliza de forma gratuita produções cientificas das áreas Administração Pública e de Empresas, Contabilidade e Turismo. A segunda é uma base consolidada e possui um conjunto de periódicos científicos brasileiros. Este estudo se concentra em publicações nacionais o que justifica a escolha das bases.

Para a realização da busca dos artigos foram utilizadas as palavras-chaves: "empreendedorismo público", "empreendedorismo no setor público", "intraempreendedorismo no setor público" e "empreendedorismo político". Realizou-se a busca de estudos somente em português que abordem o contexto brasileiro e que estejam publicados periódicos nacionais, no período de 2009 a 2019, com o texto disponível de forma completa e aberto. Foi realizado o download dos artigos encontrados e separados em pastas conforme a palavra-chave e posteriormente as informações como título, autor e ano de publicação foram dispostos em uma planilha no software Microsoft Excel, separados em duas abas, sendo a primeira continha os artigos encontrados no Spell e a segunda os estudos encontrados no Scielo. A busca e operacionalização da planilha foi realizada no início do mês de novembro de 2019.

Após a construção desta base de dados com os artigos encontrados, foi realizado uma triagem com a eliminação dos artigos repetidos que estavam na planilha, adotando a 
classificação de A a Z no Microsoft Excel, o que possibilitou a observação do título, autor e ano de publicação, após a confirmação da repetição dos trabalhos os mesmos foram eliminados.

Para a elegibilidade dos artigos foi adotado como critérios de exclusão: a) estudos com foco diferentes do setor público; b) estudos que abordem contexto internacional e; c) estudos que não contenham em seus títulos as palavras relacionadas com empreendedorismo e/ou intraempreendedorismo. Para identificar os artigos com o foco diferentes do setor público, adotou-se a leitura do título, resumo e metodologia. Por meio da leitura do título foram eliminados os artigos com o locus de estudos internacional e que não continham palavras relacionadas ao empreendedorismo ou intraempreendedorismo. Foram identificados dois artigos apresentados na base Spell com o título em português, mas quando foi realizado a leitura, estavam no idioma estrangeiro, sendo então eliminado. Deste modo, optou-se em utilizar artigos em português que permitiram compreender como tem sido absorvido o conceito de empreendedorismo no setor público e como tem sido produzido, além de permitir conhecer a maturidade dos pesquisadores em relação ao uso de métodos científicos no campo do empreendedorismo, especificamente, no setor público. A Figura 1 apresenta a síntese do processo de seleção dos artigos.

Figura 1: Fluxo de informação com as etapas com base no Prisma

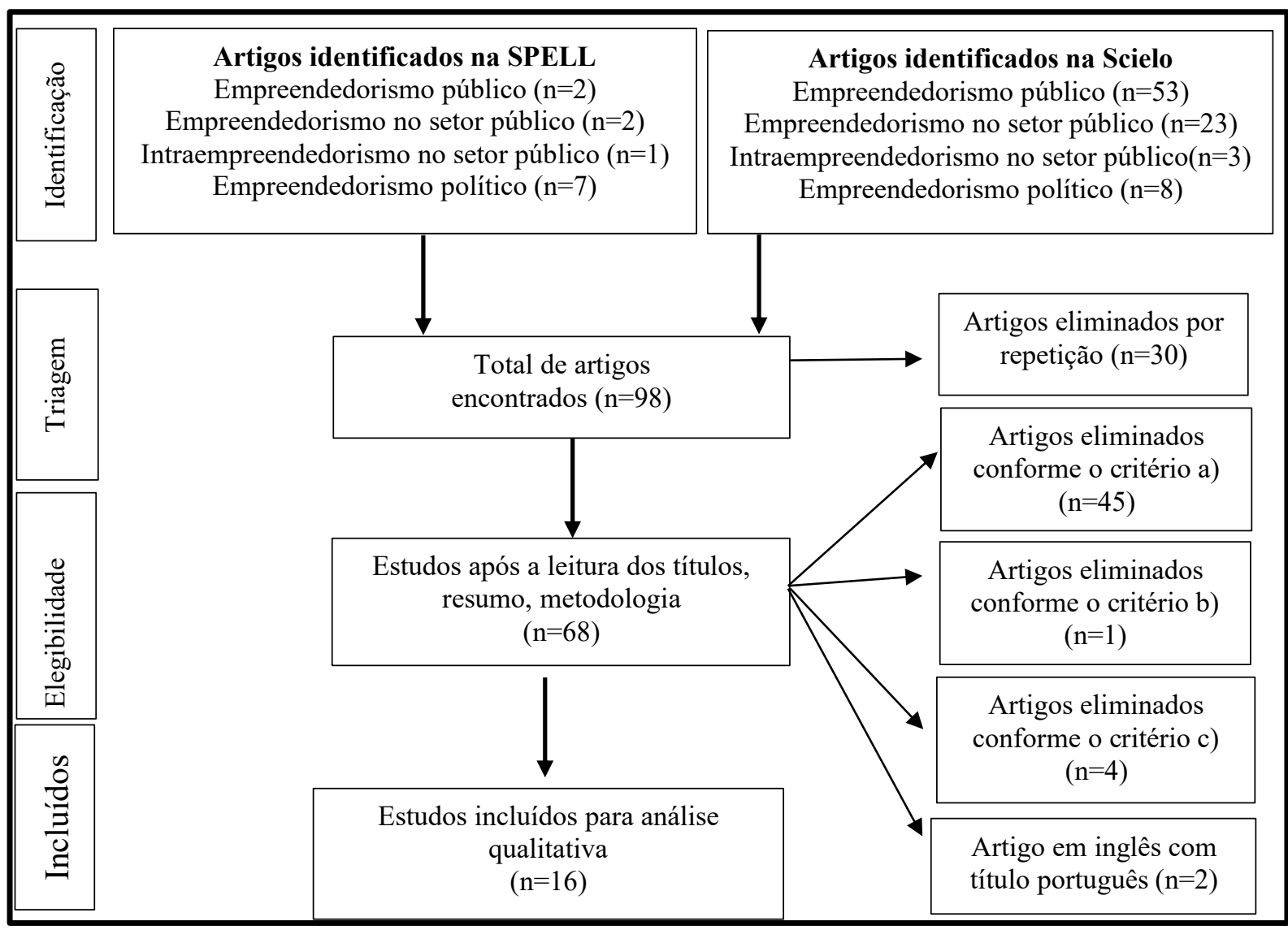

Fonte: Adaptado de Galvão, Pansani e Harrad (2015). 
Observa-se na figura 1, que com aplicação das estratégias de busca nas bases de dados Spell e Scielo, foram encontrados 98 artigos, sendo destes 30 duplicados que foram eliminados. Para a elegibilidade dos artigos foram adotados critérios de exclusão o que retirou do estudo mais 50 artigos.

Foram identificados 2 artigos que estavam com o título em português, mas o conteúdo em língua estrangeira que também foram eliminados. Ao final restaram 16 estudos que foram incluídos na revisão sistemática. Estes artigos atenderam os critérios adotados de seleção e possuem uma perspectiva teoria e empírica sobre o empreendedorismo no setor público.

Para extração dos dados dos artigos selecionados, criou-se uma tabela no Microsoft Excel contendo as seguintes informações: título, autores, filiação institucional, revista, ano de publicação que são apresentados no Quadro 1 e na Figura 1. Foram também colocados aspectos quanto aos métodos científicos como abordagem, técnicas, coleta de dados e análise dos dados que são apresentados no Quadro 2. Este instrumento permitiu descrever e identificar quais as principais organizações, revistas e a localidade da filiação dos autores que estão publicando sobre empreendedorismo no setor público.

A análise dos estudos encontrados foi realizada de modo descritivo, sendo uma revisão sistemática qualitativa e em duas etapas: a primeira compreende a análise das informações do instrumento mencionado anteriormente e o segundo apresenta o desfecho, dando foco na metodologia cientifica utilizadas pelos autores para compreender o empreendedorismo no setor público.

\section{$3 \quad$ Resultados}

Primeiramente, dos artigos analisados, observou-se a predominância de professores e estudantes de graduação e pós-graduação de universidades públicas, enquanto autores dos estudos sobre empreendedorismo no setor público. Não foram encontrados estudos nos períodos de 2011 e 2012 tendo como base os critérios utilizados nesta RSL. Deste modo, constatou-se que apesar da relevância do tema no contexto internacional ainda existem poucos estudos voltados para o empreendedorismo no setor público no Brasil.

O Quadro 1 apresenta os artigos selecionados nesta pesquisa, abordando a referência, o título e a revista científica em que o estudo foi publicado. Adotou-se como identificação uma codificação sendo de A1 a A16, tendo como base a ordem crescente em relação ao ano de publicação dos estudos.

Quadro 1: Estudos selecionados para realização da Revisão Sistemática de Literatura

\begin{tabular}{|l|l|l|l|}
\hline Cod. & Referência & Título & Revista Científica \\
\hline A1 & $\begin{array}{l}\text { Sousa; Paiva } \\
\text { Junior; Lira } \\
(2010)\end{array}$ & $\begin{array}{l}\text { A abordagem multidimensional do do } \\
\text { empreendedorismo no setor público: o } \\
\text { caso da ação empreendedora da } \\
\text { Fundação Joaquim Nabuco }\end{array}$ & $\begin{array}{l}\text { Revista de Gestão e } \\
\text { Planejamento }\end{array}$ \\
\hline A2 & Coelho (2010) & $\begin{array}{l}\text { Intraempreendedorismo a inovação } \\
\text { na gestão pública federal }\end{array}$ & $\begin{array}{l}\text { Revista do Serviço } \\
\text { Público Brasília }\end{array}$ \\
\hline A3 & $\begin{array}{l}\text { Flory; } \\
\text { Andreassi; } \\
\text { Teixeira (2013) }\end{array}$ & $\begin{array}{l}\text { Políticas de } \\
\text { Empreendedorismo para a População }\end{array}$ & $\begin{array}{l}\text { Cadernos Gestão Pública } \\
\text { e Cidadania }\end{array}$ \\
\hline
\end{tabular}




\begin{tabular}{|c|c|c|c|}
\hline & & $\begin{array}{l}\text { de Baixa Renda: Transformando } \\
\text { Necessidades em Oportunidades }\end{array}$ & \\
\hline A4 & $\begin{array}{l}\text { Valadares e } \\
\text { Emmendoerfer } \\
(2015)\end{array}$ & $\begin{array}{l}\text { A Incorporação do Empreendedorismo } \\
\text { no Setor Público: reflexões baseadas no } \\
\text { contexto brasileiro }\end{array}$ & $\begin{array}{l}\text { Revista Ciência em } \\
\text { Administração }\end{array}$ \\
\hline A5 & $\begin{array}{l}\text { Morais; } \\
\text { Valadares; } \\
\text { Emmendoerfer; } \\
\text { Tonelli (2015) }\end{array}$ & $\begin{array}{l}\text { Polissemias do empreendedorismo no } \\
\text { setor público }\end{array}$ & $\begin{array}{l}\text { Revista } \\
\text { Empreendedorismo de } \\
\text { Gestão de Pequenas } \\
\text { Empresas }\end{array}$ \\
\hline A6 & $\begin{array}{l}\text { Silva; } \\
\text { Valadares; } \\
\text { Andrade } \\
(2016)\end{array}$ & $\begin{array}{l}\text { Ações Empreendedoras } \mathrm{Na} \text { Gestão } \\
\text { Pública: análise do programa crédito } \\
\text { solidário (PCS) em um município do } \\
\text { sul de Minas Gerais }\end{array}$ & $\begin{array}{l}\text { Revista Eletrônica de } \\
\text { Ciência Administrativa }\end{array}$ \\
\hline A7 & $\begin{array}{l}\text { Pereira; } \\
\text { Oliveira; } \\
\text { Valadares; } \\
\text { Emmendoerfer } \\
(2016)\end{array}$ & $\begin{array}{l}\text { Comportamento empreendedor no } \\
\text { setor público: análise comparada de } \\
\text { dois presidentes do Brasil }\end{array}$ & $\begin{array}{lr}\text { Revista } & \text { de } \\
\text { Empreendedorismo e } \\
\text { Gestão de Pequenas } \\
\text { Empresas }\end{array}$ \\
\hline A8 & $\begin{array}{l}\text { Borges; } \\
\text { Romaniello; } \\
\text { Brito (2016) }\end{array}$ & $\begin{array}{l}\text { Empreendedorismo No Setor Público: } \\
\text { A Influência Das Características } \\
\text { Organizacionais }\end{array}$ & $\begin{array}{lr}\text { Revista } & \text { de } \\
\text { Empreendedorismo e } \\
\text { Gestão de Pequenas } \\
\text { Empresas }\end{array}$ \\
\hline A9 & $\begin{array}{l}\text { Arana e Silva } \\
(2016)\end{array}$ & $\begin{array}{l}\text { Empreender: Um Novo Olhar Sobre a } \\
\text { Gestão Pública Brasileira }\end{array}$ & GESTÃO.ORG \\
\hline A10 & $\begin{array}{l}\text { Resende; } \\
\text { Emmendoerfer; } \\
\text { Valadares; } \\
\text { Lima (2017) }\end{array}$ & $\begin{array}{l}\text { Atuação de empreendedores públicos } \\
\text { na formulação de um programa de } \\
\text { apoio ao desenvolvimento juvenil }\end{array}$ & $\begin{array}{l}\text { REA Revista De } \\
\text { Administração Da UFSM }\end{array}$ \\
\hline A11 & $\begin{array}{l}\text { Valadares; } \\
\text { Alcântara; } \\
\text { Vilas Boas; } \\
\text { Emmendoerfer } \\
(2017)\end{array}$ & $\begin{array}{l}\text { Os discursos do empreendedorismo na } \\
\text { administração pública brasileira: } \\
\text { análise crítica de uma experiência } \\
\text { contemporânea }\end{array}$ & $\begin{array}{l}\text { REA Revista De } \\
\text { Administração Da UFSM }\end{array}$ \\
\hline A12 & $\begin{array}{l}\text { Lapolli e } \\
\text { Gomes (2017) }\end{array}$ & $\begin{array}{l}\text { Práticas intraempreendedoras na gestão } \\
\text { pública: um estudo de caso na Embrapa }\end{array}$ & Estudos Avançados \\
\hline A13 & $\begin{array}{l}\text { Silva; Meza; } \\
\text { Oliveira; } \\
\text { Procopiuck } \\
(2018)\end{array}$ & $\begin{array}{l}\text { Intraempreendedorismo no Setor } \\
\text { Público: Análise do Comportamento } \\
\text { Empreendedor de Gestores Públicos } \\
\text { Municipais por Meio do Carland } \\
\text { Entrepreneurship Index (CEI) }\end{array}$ & $\begin{array}{l}\text { Revista } r \text { de } \\
\text { Empreendedorismo e } \\
\text { Gestão de Pequenas } \\
\text { Empresas }\end{array}$ \\
\hline A14 & $\begin{array}{l}\text { Costa Filho; } \\
\text { Gomes; } \\
\text { Teixeira (2018) }\end{array}$ & $\begin{array}{l}\text { Ações Empreendedoras Inovadoras No } \\
\text { Setor Público }\end{array}$ & $\begin{array}{l}\text { Revista Brasileira de } \\
\text { Gestão e Inovação }\end{array}$ \\
\hline
\end{tabular}




\begin{tabular}{|l|l|lr|l|}
\hline A15 & $\begin{array}{l}\text { Lima; Teixeira; } \\
\text { Dantas; } \\
\text { Almeida } \\
(2018)\end{array}$ & $\begin{array}{l}\text { Empreendedorismo público e } \\
\text { orientação empreendedora em } \\
\text { instituições federais de ensino }\end{array}$ & $\begin{array}{l}\text { Revista de Ciência da } \\
\text { Administração }\end{array}$ \\
\hline A16 & $\begin{array}{l}\text { Teixeira; } \\
\text { Andrade; } \\
\text { Alcântara e } \\
\text { Oliveira (2019) }\end{array}$ & $\begin{array}{l}\text { Inovação e Empreendedorismo: Um } \\
\text { Caso No Setor Público }\end{array}$ & Pretexto \\
\hline
\end{tabular}

Fonte: Elaboração nossa.

Observa-se com base no Quadro 1, que existem autores que participaram de publicação mais de uma vez, dando continuidade aos estudos de empreendedorismo no setor público. O ano de 2016 apresenta-se no Quadro 1, como sendo o ano com maior publicação sobre o tema, totalizando quatro estudos. O tema tem sido estudado de diversas formas, seja de modo como empreendedorismo institucional ou de políticas como apontado por Emmendoerfer (2019), mas existem alguns estudos que apresenta o empreendedorismo na perspectiva do Estado empreendedor, de Mazzucato (2014). O empreendedorismo é apresentado por Morais et al. (2015) como um conceito polissêmico. As revistas em que os estudos foram publicados possuem Qualis de A2 a B3 na classificação do periódico do quadriênio 2013 a 2016. Observase que as revistas Ciência em Administração, Administração da UFSM e Empreendedorismo e Gestão de Pequenas Empresas apresentam mais de uma publicação relacionada ao empreendedorismo no setor público.

A figura 2, apresenta um mapa dos estados em que estão localizadas as instituições onde os autores dos artigos apresentados no Quadro 1 estão filiados.

Figura 2: Os estados onde estão localizadas as instituições dos autores

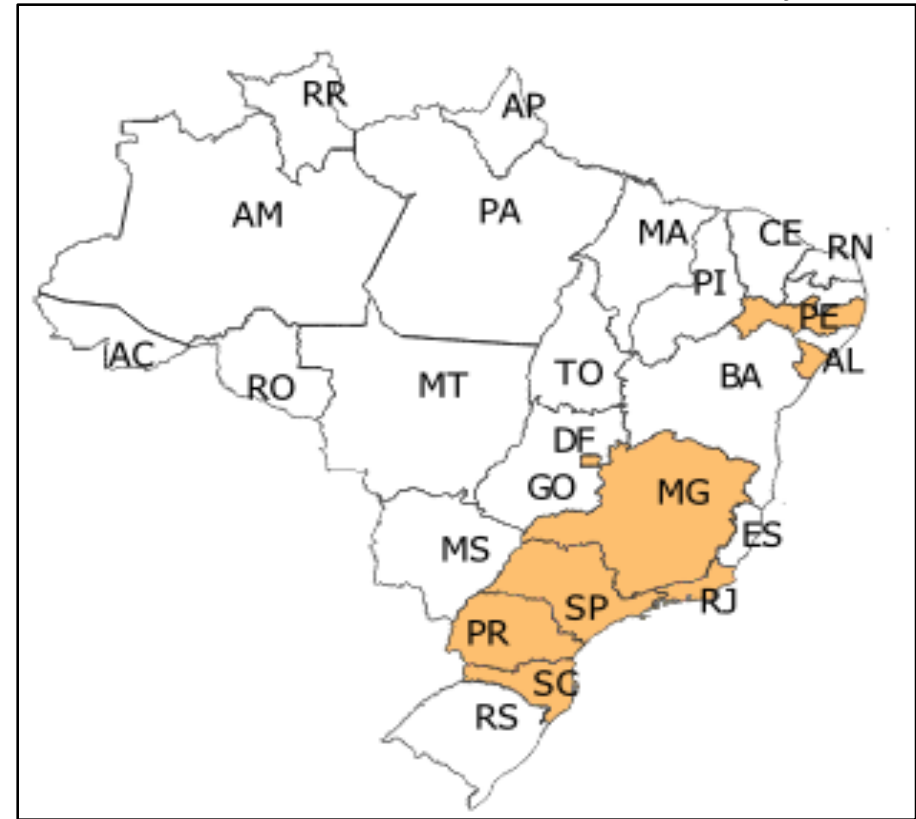

Fonte: Elaboração nossa. 
Com base no levantamento realizado neste estudo, contatou-se que existe uma concentração dos estudos voltados para o empreendedorismo no setor público no Sudeste especificamente em Minas Gerais nas Universidades Federais de Viçosa, Lavras, Minas Gerais e na Fundação João Pinheiro. Estas universidades são responsáveis por 8 estudos apresentados no Quadro 1. Existe um estudo no Rio de Janeiro apresentado pela Fundação Getúlio Vargas e um estudo em São Paulo apresentado pela Universidade do Oeste Paulista.

$\mathrm{Na}$ região Sul, os estudos voltados para o empreendedorismo no setor público, apresentam-se nos estados do Paraná e Santa Catarina. No Paraná as filiações dos autores são representadas por duas universidades, sendo a Universidade Federal do Paraná e a Pontifícia Universidade Católica do Paraná. Vale ressaltar, que o trabalho de Silva et al. (2017), foi realizado em parceiras com autores do Paraná e Santa Catarina. O segundo Estado que representa a região Sul é Santa Catarina que apresenta um estudo que é o de Lapolli e Gomes (2017), representando a Universidade Federal de Santa Catarina.

A região nordeste apresenta três estudos, localizados nos estados de Pernambuco e Sergipe. O primeiro é representado pela Universidade Federal de Pernambuco e a Fundação Joaquim Nabuco com o estudo de Souza (2010). O segundo estado, apresenta dois estudos realizado na Universidade Federal de Sergipe por Costa Filho, Gomes (2018) e Lima et al. (2018). No centro-oeste, o estudo encontrado foi de Coelho (2010), sendo uns dos primeiros estudos voltado para o empreendedorismo no setor público. A autora tem como filiação a Universidade de Brasília.

Assim, pode-se observar que existe uma concentração de estudos voltados para o empreendedorismo no setor público no Sudeste do Brasil, em especial no estado de Minas Gerais. Contudo, vale ressaltar que existem esforços de compreender o fenômeno do empreendedorismo aplicado ao setor público em outros estados do Brasil. Ressalta-se que essa concentração de estudos em Minas Gerais pode estar associado as práticas de apropriação do Empreendedorismo no Setor Público ocorridas no período de 2003 a 2010, durante a modernização deste governo subnacional (Valadares, Emmendoerfer, 2015). Não foi encontrado estudos no Norte do Brasil em relação ao tema, isto deve ser pelo fato de que ainda existem poucos programas de mestrados e doutorados em administração ou gestão pública neste território.

\section{$4 \quad$ Métodos científicos em Estudos sobre Empreendedorismo no Setor Público no Brasil}

Dos 16 artigos selecionados tendo como base os critérios estabelecidos pela RSL, encontrou-se diferentes abordagens, técnicas de coleta e de análise dos dados que foram expostos no Quadro 2.

Quadro 2: Metodologias cientificas empregadas nos estudos identificados.

\begin{tabular}{|l|l|l|l|}
\hline Cod. & Abordagem & Coleta de Dados & Análise dos Dados \\
\hline A1 & Qualitativa & Não mencionado & Análise de Conteúdo \\
\hline A2 & Qualitativa & Documental e Entrevista & Não mencionado \\
\hline A3 & Não mencionado & $\begin{array}{l}\text { Análise documental, entrevista } \\
\text { e questionário }\end{array}$ & Não mencionado \\
\hline A4 & Não mencionado & Revisão de literatura & $\begin{array}{l}\text { Não se aplica (artigo } \\
\text { teórico) }\end{array}$ \\
\hline
\end{tabular}




\begin{tabular}{|c|c|c|c|}
\hline A5 & Qualitativa & Revisão de bibliográfica & Análise de Conteúdo \\
\hline A6 & Qualitativa & $\begin{array}{l}\text { Entrevista e questionário } \\
\text { semiestruturado }\end{array}$ & Análise de conteúdo \\
\hline A7 & Qualitativa & Bibliográfico e documental & Análise de conteúdo \\
\hline A8 & Quantitativos & $\begin{array}{l}\text { Survey, entrevistas } \\
\text { observação, diário de campo. }\end{array}$ & Não mencionado \\
\hline A9 & Qualitativa & Revisão bibliográfica & $\begin{array}{l}\text { Não se aplica (artigo } \\
\text { teórico) }\end{array}$ \\
\hline A10 & Qualitativa & $\begin{array}{l}\text { Bibliografias, documentos } \mathrm{e} \\
\text { entrevista }\end{array}$ & Análise de Conteúdo \\
\hline A11 & Qualitativo & Bibliográfico e documental & $\begin{array}{l}\text { Análise de Discurso } \\
\text { Crítica }\end{array}$ \\
\hline A12 & Qualitativa & $\begin{array}{l}\text { Revisão de literatura } \mathrm{e} \\
\text { entrevista semiestruturada }\end{array}$ & Não mencionado \\
\hline A13 & Qualitativa & Questionário online & Não mencionado \\
\hline A14 & Qualitativa & Pesquisa documental & Análise de conteúdo, \\
\hline $\mathrm{A} 15$ & Quantitativo & Survey & Análise fatorial \\
\hline A16 & Qualitativa. & $\begin{array}{l}\text { Entrevista semiestruturada, } \\
\text { bloco de notas, observação } \\
\text { participante }\end{array}$ & Análise de conteúdo \\
\hline
\end{tabular}

Fonte: Elaboração nossa.

O quadro 2 apresenta quanto a abordagem dos estudos voltados para o empreendedorismo no setor público. O método qualitativo considera a subjetividade do sujeito que não são traduzidas em números (VIEIRA; ZOUAIN, 2005; KAUARK; MANHÃES; MEDEIROS, 2010). A pesquisa quantitativa busca a objetividade, as relações causais e a generalização dos fatos (VIEIRA; ZOUAIN, 2005). O método qualitativo busca por meio da subjetividade explicar os fenômenos estudados. Já os métodos quantitativos utilizam-se dos métodos estatísticos para explicar os fenômenos estudados.

Com base no quadro 2, observa-se que 12 artigos científicos encontrados afirmam que utilizam a abordagem qualitativa nos estudos sobre empreendedorismo no setor público, apenas 2 afirmam utilizar a abordagem quantitativa e 2 não apresentaram a abordagem utilizada em seus estudos. Com uma leitura aprofundada na metodologia dos estudos listados no quadro 2, apesar de não esclarecer a abordagem utilizada, identificou-se que os artigos A3 tem como abordagem quali-quantitativa, já o estudo A4 que tem como abordagem os estudos qualitativos.

Ainda no que tange a abordagem, observou-se com a leitura da metodologia que o estudo A8 apresenta indícios de utilização da abordagem qualitativa, com a utilização de duas técnicas de coletas de dados sendo a entrevista e a observação participante, o que pode ser considerado uma pesquisa quali-quantitativa. Foi também observado no estudo A13 que utiliza Carland Entrepreneurship Index (CEI), que por sua vez faz uso dos métodos estatístico para avaliar o perfil empreendedor, assim este utiliza de uma abordagem qualitativa e sim quantitativa. Contudo, o questionário aplicado faz uso de três questões abertas que podem ser analisadas de modo qualitativo. 
Quanto a técnica de coleta de dados, utilizou-se nos artigos a pesquisa documental, entrevista, questionário (survey), revisão de literatura e bibliográfica, observação participante e diário de campo (bloco de notas).

A primeira técnica de acordo com Brandão e Nogueira (2011) possibilita um aprofundamento do conhecimento sobre um determinado assunto. Neste sentido Cellard (2008) afirma que os documentos compreenderem o tempo e as questões sociais, neste sentido o autor apresenta que existem documentos públicos e privados, que devem ser esclarecidos quanto a autenticidade destes documentos e a fonte. Neste sentido, os trabalhos A1 e A2 apesar de utilizar a técnica de pesquisa documental não expõe.

No artigo A7, os autores afirmam que utilizaram a pesquisa documental e bibliográfica, contudo apresentam um conjunto de artigos e livros para a realização da analisar o comportamento empreendedor no setor público. Assim, este estudo utiliza como método somente a pesquisa bibliográfica.

Em relação a entrevista, o artigo A2 não apresentou quais os instrumentos utilizados como gravador e quais categorias que foram utilizados para análise. No artigo A6, apesar de apresentar a utilização a entrevista, afirma que utiliza um questionário com questões semiestruturadas. Acredita-se que seja não um questionário, mas um roteiro semiestruturado.

Os artigos A8 e A16 como complementariedade da observação participante utilizaram o diário de campo para registrar o que estava sendo percebido no campo, contudo somente o último apresenta a forma de utilização desta ferramenta de coleta de dados.

$\mathrm{Na}$ análise dos dados, a estratégia mais utilizada pelos autores para a compreensão do fenômeno do empreendedorismo no setor público foi a análise de conteúdo. Os artigos A1, A5, A6, A10, A14 e A15 utilizam a técnica de análise de conteúdo apresentado por Bardin (2011) que apresenta um esquema em três etapas pré-análise, exploração do material e tratamento dos resultados. Os artigos A7 e A16 apresentam a análise de conteúdo, mas somente as categorias de análise. $\mathrm{O}$ artigo A11 apresenta como estratégia de análise, o discurso crítico. No entanto, existem cinco artigos (A2, A3, A8, A12, A13) que não apresentam suas estratégias de análise, o que compromete a qualidade dos artigos quanto ao método, o entendimento do avaliador $\mathrm{e}$ dos leitores.

Os artigos indicam como uso para prezar a qualidade e a confiabilidade cientifica a triangulação e análise do conselho de ética. Sendo o primeiro, apresentado pelos artigos A1, A8, A10, A14, A16 e o segundo pelo artigo A13. Observa-se que somente 6 artigos apresentam algum recurso visando a confiabilidade cientifica.

\section{Considerações Finais}

Apesar da importância empírica e cientifica sobre o empreendedorismo no setor público, ainda existem poucos estudos que abordem o tema no Brasil, considerados os artigos publicados na língua nacional nas bases SPELL e SCIELO. Os 16 estudos encontrados por meio da técnica de seleção utilizada, constou-se que grande parte dos pesquisadores que estudam estes temas estão filiados a organizações públicas no Sudeste do Brasil, sendo que no Norte não foram encontrados nenhum estudo sobre o tema.

De modo geral, os estudos encontrados abordam sobre o empreendedor institucional (intraempreendedor), empreendedor de políticas ou o estado sendo empreendedor. Estes estudos estão publicados em 9 revistas, sendo as que possuem mais estudos são as revistas 
científicas: Revista de Ciências em Administração (RCA/UFSC), Revista de Administração da UFSM (ReA/UFSM) e Revista de Empreendedorismo e Gestão de Pequenas Empresas (REGEPE).

Em resposta a questão problema, identificou-se como métodos científicos utilizados em pesquisas voltadas para empreendedorismo no setor público, uma predominância de estudos qualitativos, com o procedimento de coleta de dados realizado por meio da pesquisa documental, entrevista, questionário (survey), revisão de literatura e bibliográfica, observação participante e diário de campo. Como estratégia da análise dos dados, tem-se utilizado analise de conteúdo e Análise de Discurso Crítica nos estudos qualitativos e nos estudos quantitativos análise fatorial. Observou-se algumas incongruências na utilização da abordagem e nas técnicas utilizadas para a coleta de dados. Existem alguns estudos que não apresentam suas estratégias de analises o que prejudica o rigor e a confiabilidade da pesquisa.

Conclui-se, que é necessário avanços quanto a compreensão da utilização dos métodos científicos nos estudos voltados para o empreendedorismo no setor público no contexto brasileiro para que possa garantir o rigor e a confiabilidade da pesquisa. Vale ressaltar que é possível e saudável para o avanço do conhecimento científico, considerar a pluralidade na utilização de outras técnicas de pesquisa científica como grupo focal, método biográfico, história oral, pesquisa-ação e outras que permitam conhecer com maior profundidade e sob outras perspectivas o fenômeno estudado, nesse caso, o Empreendedorismo no Setor Público.

\section{Referências}

ARANA, Alba Regina Azevedo; SILVA, Murilo Alves da. Empreender: Um Novo Olhar Sobre a Gestão Pública Brasileira. Revista Gestão. Org, v. 14, n. 1, p. 146-157, 2016.

BELTRÃO, Ricardo Ernesto Vasque; NOGUEIRA, Fernando A. A pesquisa documental nos estudos recentes em administração pública e gestão social no Brasil. In: XXXV Encontro Nacional da Associação Nacional de Pós-Graduação e Pesquisa em Administração. Anais do XXXV Encontro Nacional da Associação Nacional de Pós-Graduação e Pesquisa em Administração, 2011.

BORGES, Denise Aparecida Hipólito; ROMANIELLO, Marcelo Marcio; BRITO, Mozar José de. Empreendedorismo no setor público: a influência das características organizacionais. Revista de Empreendedorismo e Gestão de Pequenas Empresas, v. 5, n. 1, p. 85-117, 2016.

CELLARD, André. A análise documental. In: POUPART, J.; DESLAURIERS, J.P.; GROULX, L. H.; LAPERRIERE, A.; MAYER, R.; PIRES, A. (Orgs.). A pesquisa qualitativa. Enfoques epistemológicos e metodológicos. São Paulo, Editora Vozes, 2008.

COELHO, Meire Lúcia Gomes Monteiro Mota. Intraempreendedorismo e a inovação na gestão pública federal. Revista do Serviço Público, v. 61, n. 3, p. 233-247, 2010.

COSTA FILHO, Edson; DE ARAÚJO GOMES, Maria Alvina; TEIXEIRA, Rivanda Meira. Ações Empreendedoras Inovadoras No Setor Público. Revista Brasileira de Gestão e Inovação (Brazilian Journal of Management \& Innovation), v. 5, n. 2, p. 1-29, 2017.

CRESWELL, John W. Research Design: qualitative, quantitative and mixed methods approaches (2nd ed.). London: Sage Publications, 2003 
DRESCH, Aline; LACERDA, Daniel Pacheco; JÚNIOR, José Antonio Valle Antunes. Design science research: método de pesquisa para avanço da ciência e tecnologia. Bookman Editora, 2015.

EMMENDOERFER, Magnus Luiz. Inovação e empreendedorismo no setor público. Brasília: Enap, 2019.

FLORY, Henrique; ANDREASSI, Tales; TEIXEIRA, Marco Antonio Carvalho. Políticas Públicas de Empreendedorismo para a População de Baixa Renda: Transformando Necessidades em Oportunidades. Cadernos Gestão Pública e Cidadania, v. 18, n. 62, 2013.

GALVÃO, Taís Freire; PANSANI, Thais de Souza Andrade; HARRAD, David. Principais itens para relatar Revisões sistemáticas e Meta-análises: A recomendação PRISMA. Epidemiologia e Serviços de Saúde, v. 24, p. 335-342, 2015.

KAUARK, Fabiana da Silva.; MANHÃES, Fernanda Castro.; MEDEIROS, Carlos Hernique. Metodologia da pesquisa: guia prático. Itabuna: Via Litterarum, 2010.

KINGDON, John W. Agendas, alternatives, and public policies. New York: Harper Collins, 2003.

LAPOLLI, Édis; GOMES, Roberto Kern. Práticas intraempreendedoras na gestão pública: um estudo de caso na Embrapa. Estudos Avançados, v. 31, n. 90, p. 127-142, 2017.

LIMA, Simone Freitas Araújo; DANTAS, Cristiane Feitoza; TEIXEIRA, Rivanda Meira; ALMEIDA, Moisés Araújo. Empreendedorismo público e orientação empreendedora em instituições federais de ensino. Revista de Ciências da Administração, v. 20, n. 50, p. 44-60, 2018.

MORAIS, Mateus Cerqueira Anício; VALADARES, Josiel Lopes; EMMENDOERFER, Magnus; TONELLI, Dany. Polissemias do empreendedorismo no setor público. Revista de Empreendedorismo e Gestão de Pequenas Empresas, v. 4, n. 1, p. 26-53, 2015.

OSBORNE, David; GAEBLER, T. Reinventando o governo: como o espírito empreendedor está transformando o governo. Brasília: MH Comunicação, 1994.

PEREIRA, Isabella Monteiro; OLIVEIRA, Denis Renato de; VALADARES, Josiel Lopes; EMMENDOERFER, Magnus Luiz. Comportamento Empreendedor No Setor Público: Análise Comparada De Dois Presidentes Do Brasil. Revista de Empreendedorismo e Gestão de Pequenas Empresas, v. 5, n. 2, p. 51-76, 2016.

RESENDE, Tamiris Cristhina et al. Atuação de empreendedores públicos na formulação de um programa de apoio ao desenvolvimento juvenil. Revista de Administração da Universidade Federal de Santa Maria, v. 10, n. 2, p. 318-337, 2017.

SILVA, Camila Assis; VALADARES, Josiel Lopes; ANDRADE, Daniela Meirelles. Ações empreendedoras na gestão pública: análise do Programa Crédito Solidário (PCS) em um município do sul de Minas Gerais. Revista Eletrônica de Ciência Administrativa, v. 15, n. 1, p. 25-39, 2016.

SILVA, Marcus Vinicius Gonçalves da; MEZA, Maria Lúcia Figueiredo Gomes de; OLIVEIRA, Antonio Gonçalves de; PROCOPIUCK, Mário. Intraempreendedorismo no Setor 
Público: Análise do Comportamento Empreendedor de Gestores Públicos Municipais por Meio do Carland Entrepreneurship Index (CEI). Revista de Empreendedorismo e Gestão de Pequenas Empresas, v. 7, n. 2, p. 67-114, 2018.

SOUSA, Jefferson Lindberght de.; PAIVA JUNIOR, Fernando Gomes de; LIRA, Zarah. Barbosa. A abordagem multidimensional do empreendedorismo no setor público: o caso da ação empreendedora da fundação Joaquim Nabuco. Revista Gestão e Planejamento, Salvador, v. 11, n. 2, p. 337-354, 2010.

TEIXEIRA, Thatiana Stacanelli; ANDRADE, Daniela Meirelles; ALCÂNTARA, Valderi de Castro; OLIVEIRA, Naiara Kasmin de . Inovação e empreendedorismo: Um caso no setor público. Revista Pretexto, v. 20, n. 1, p. 57-71, 2019.

VALADARES, Josiel Lopes; DE CASTRO ALCÂNTARA, Valderí; VILAS BOAS, Ana Alice; EMMENDOERFER, Magnus Luiz. Os discursos do empreendedorismo na administração pública brasileira: análise crítica de uma experiência contemporânea. Revista de Administração da Universidade Federal de Santa Maria, v. 10, n. 6, p. 990-1008, 2017.

VALADARES, Josiel; EMMENDOERFER, Magnus. A incorporação do empreendedorismo no setor público: reflexões baseadas no contexto brasileiro. Revista de Ciências da Administração, v. 1, n. 1, p. 82-98, 2015.

VIEIRA, Marcelo Milano Falcão; ZOUAIN, Deborah Moraes. Pesquisa qualitativa em administração. Rio de Janeiro: FGV, 2005.

\footnotetext{
${ }^{1}$ Essa frase faz uma alusão à obra “O que faz o brasil, Brasil?" do antropólogo Roberto da Matta publicada pela editora Rocco em 1999 que propõe o questionamento de temas tais como o que é democracia? como se compara sociedades? e, principalmente, como se percebe as diferenças históricas e culturais que conferem uma especificidade toda própria a cada sociedade singular? Esta última indagação inspirou a discussão deste trabalho sobre o posicionamento do Brasil frente a produção científica sobre o tema de interesse internacional como o Empreendedorismo no Setor Público.
} 